REVISTA

Actualidades Investigativas en Educación

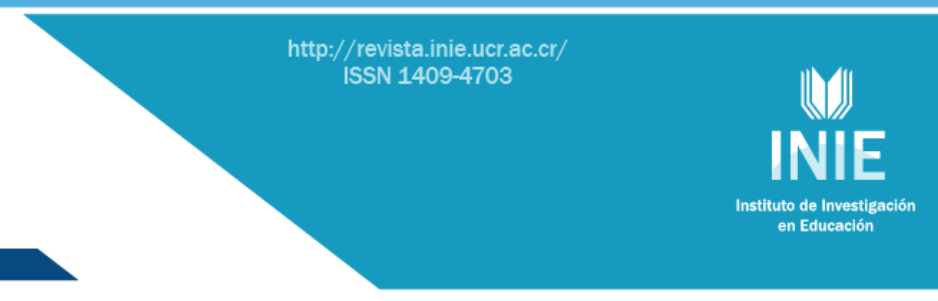

\title{
LAS MUSAS DE PRINCIPIO DEL SIGLO XXI: INDICIOS DEL
} CAMBIO EDUCATIVO MUSEAL

MUSES OF THE XXI CENTURY: EVIDENCE OF EDUCATIONAL CHANGE IN MUSEUMS

\section{Volumen 12, Número 2}

Mayo-Agosto

pp. $1-15$

Este número se publicó el 30 de mayo de 2012

Keilyn Rodríguez Sánchez

Revista indizada en REDALYC

Revista distribuida en las bases de datos:

CATÁLOGO DE LATINDEX, IRESIE, CLASE, DIALNET, DOAJ, E-REVIST@S,

Revista registrada en los directorios:

ULRICH'S, REDIE, RINACE, OEI, MAESTROTECA, PREAL, HUASCARAN, $\underline{\text { CLASCO }}$ 


\title{
LAS MUSAS DE PRINCIPIO DEL SIGLO XXI: INDICIOS DEL CAMBIO EDUCATIVO MUSEAL
}

\author{
MUSES OF THE XXI CENTURY: EVIDENCE OF EDUCATIONAL CHANGE IN MUSEUMS
}

\author{
Keilyn Rodríguez Sánchez ${ }^{1}$
}

\begin{abstract}
Resumen: Este ensayo expone que la audiencia es el punto de partida para identificar la mejor manera de diseñar experiencias sensoriales de entretenimiento o educación, es el objeto de la investigación museal, sus gustos e intereses se constituye en el eje de los estudios y de las campañas de mercado. Todo el quehacer museal se orienta a satisfacer los gustos y necesidades del sujeto-visitante para así atraerlo al Museo. Este nuevo enfoque museológico tiene el riesgo de olvidar el objeto en el proceso educativo y centrarse en el sujeto. Se propone la promoción del diálogo sujeto-objeto para que la función educativa del Museo contribuya a la conformación de una sociedad con conciencia histórica-cultural clara. Se concluye que, en las primeras décadas del Siglo XXI los diferentes enfoques de la sociomuselogía, la museografía interactiva, la museología crítica y dialógica, así como los ejes de cambio generados por las innovaciones tecnológicas, las dinámicas de consumo y las comunidades de aprendizaje, apuntan a que la audiencia es el centro de atención, y no el objeto y la forma de ser expuesto como lo fue en el Siglo XX.
\end{abstract}

Palabras clave: MUSEOLOGÍA, MERCADEO, MUSEOGRAFÍA, NUEVAS TECNOLOGÍAS.

Abstract: This paper presents an allegory between the muses of Greek mythology as the inspiration of memory, knowledge and the arts and the role of muses in inspiring current museum's tasks in the twenty-first century on the worldwide stage, in order to systematize the emerging museological XXI century currents and the central axes of change that are developing in this period. It concludes that in this century different museological approaches to sociomuseology, interactive museography and critical dialogical museology as well as the axes of change generated by technological innovations, the dynamics of consumption and learning communities, suggest that the individual visitor is the main target, and not the object and how it is exhibited (as in the last century). Thus, the individual visitor is the starting point for identifying the best way to design sensory experiences of entertainment or education, he/she is the subject of museum research, his/her likes and interests are the axis of the studies and marketing campaigns. All of the museum's focus is focused on how to satisfy the tastes and needs of the subject, and attract visitors to the Museum. This new approach has the museological risk of forgetting the object in the educational process and instead focusing on the subject. It proposes the encouragement of subject-object dialogue so that the Museum's educational function contributes to the shaping of society with clear cultural and historical awareness.

Keywords: MUSEOLOGY, MARKETING, MUSEOGRAPHY, NEW TECHNOLOGY.

\footnotetext{
${ }^{1}$ Doctorado en Educación, Licenciatura en Antropología Social, Licenciatura en Ciencias de la Educación con énfasis en Administración de Programas de Educación no Formal, todos los títulos de la Universidad de Costa Rica. Ha trabajado en el ámbito de los museos desde el año 1992. Fue funcionaria del Ministerio de Cultura y Juventud, destacada al Centro Costarricense de Ciencia y Cultura (sede del Museo de los Niños). Actualmente labora en el despacho del Viceministro de Cultura y Juventud como enlace de las Artes Literarias. Además, es profesora de la Escuela de Antropología de la Universidad de Costa Rica.
}

Direcciones electrónicas: keilyn.rodriguez@ucr.ac.cr, kerodriguez@mci.go.cr, keilynrosa@gmail.com

Artículo recibido: $1^{\circ}$ de diciembre, 2011

Aprobado: 12 de abril, 2012 


\section{Presentación}

Este ensayo tiene como objetivo central identificar los principales ejes de cambio en la museología del presente siglo y si podemos responder a la pregunta alegórica ¿cuáles son las musas que nos inspiran en el quehacer museal del siglo XXI? de seguro encontraremos las tendencias que en el presente orientan el trabajo museal.

Etimológicamente, la palabra Museo deriva del griego Movoziov (Grimal, 1994) que remite al lugar de las musas, que son las diosas inspiradoras de la memoria, de diferentes artes y ciencias, y de la historia.

Las musas que inspiran nuestro quehacer museal en el siglo XXI fueron concebidas en el siglo pasado, en el contexto de la emergente globalización económica y cultural de la humanidad, donde nos enfrentábamos, al igual que en el presente, a lo Global desde lo Local y los Museos ocuparían un espacio importantísimo en el resguardo de la herencia y en la reflexión sobre el acelerado cambio que se nos adelanta al diálogo y al análisis.

Ahora bien, Sandell y Janes (2007) editan el libro Museum Management and Marketing, donde nos señalan que los retos del siglo XXI serán: la reducción del número de visitantes a Museos, construir relaciones entre el Museo y otros campos sociales, los avances tecnológicos acelerados, el nuevo concepto de uso del tiempo libre y el uso del marketing. Este panorama nos da varios escenarios que se desarrollan en este ensayo.

Así, hacemos referencia a los ejes de cambio que se organizan en dos grandes bloques. En el primer bloque se remite a las nuevas tendencias de proyectos museológicos completos, o sea, ejes conceptuales que abarcan todo el quehacer museal, ellos son: la Musa interactiva o museografía interactiva; la Musa del poder o sociomuseología; la Musa Crítica o museología crítica y la Musa Dialógica o museología dialógica. En el segundo bloque de las tendencias de cambio para el siglo XXI, se hace referencia a ejes específicos, tales como la Musa digital que refiere a los cambios tecnológicos; la Musa del consumo que abarca las tendencias de interés a acceder a diferentes mercados en el ámbito de los museos y, por último, la Musa Museal que trata la tendencia a constituir comunidades de aprendizaje en el ámbito de los museos. Al final del ensayo se exponen las conclusiones. Antes de dar inicio al desarrollo del ensayo, es indispensable hacer explícita la vinculación inherente entre educación y museos.

Como es sabido, el Museo, además de coleccionar objetos de valor cultural e histórico e investigarlos, es en esencia un espacio educativo donde se exhibe y se educa. Esas 
exhibiciones han sido artificialmente diseñadas desde la pedagogía museográfica para la divulgación del conocimiento humano en sus diferentes expresiones (Rodríguez, 2011). Los cambios museales que se exponen en este ensayo tienen implicaciones directas en esa didáctica museográfica y en la concepción del fenómeno educativo en el ámbito.

El museo como espacio de educación no formal desde la museografía expone con una didáctica del objeto y la actividad, unos contenidos y sentidos determinados, y en el encuentro museografía-visitantes sucede lo impredecible, se construye un espacio educativo diferente al diseñado y la educación informal toma el control de los pasillos del museo y sus objetos median en interacciones humanas de formas no pre-diseñadas del todo, inadvertidas, con dinámicas interpersonales impensables. Toda esa dinámica humana sigue siendo educación.

\section{Ejes de cambio en la museología actual: las Musas del siglo XXI}

\section{Las tendencias museológicas}

\subsection{La Musa interactiva: hacia el Museo Total desde la Museografía interactiva}

En la actualidad, y desde la museografía interactiva, se propone el concepto del Museo Total (Wagensberg. 2005) que consiste en una línea museográfica que promueve tres aspectos centrales:

1. La triple interactivad: que consiste no sólo en el tradicional "hands on" del siglo pasado que es interactuar con los sentidos, sino incluye también el "minds on" que es la participación cognitiva y el "Hearts on" que consiste en la dimensión social, emocional y cultural del estar-ser-sentir junto con otros en un contexto expositivo. Interesa controlar la interacción desde el diseño museográfico con intensiones pedagógicas y con base en un profundo conocimiento de la mente humana, de la cultura de pertenencia del visitante, las formas de interacción social en el contexto museal y de la didáctica museográfica.

2. La provocación de las conversaciones: que consiste en generar con la museografía y particularmente con el objeto, conversaciones con sí mismo (pensamiento), con otros y con los objetos propiamente (observar y experimentar). Generar preguntas, dudas y no dar toda la información. El lenguaje museográfico es una forma de comunicación y de provocar comunicación, es diferente al diálogo que puede generar un reporte 
investigativo, un cuento, un programa de televisión, la Internet, entre otros.

3. El lugar de encuentro para construir opinión publica sobre lo que se expone en alianza con la academia, las comunidades, grupos organizados, centros de investigación, entre otros similares. Mediante actividades y eventos es posible convocar a los interesados y así discutir, exponer, dialogar y construir sentido sobre aquello que provoca la reunión.

No cabe duda de que la "musa" pedagógica ha inspirado a la museografía desde el siglo pasado, pero en el siglo XXI el salto con respecto a la comprensión de la interacción como recurso pedagógico ha sido una plataforma central para la museografía del siglo XXI y que tiene mucho camino por recorrer (Rodríguez, 2011). La Musa interactiva nos expone lo siguiente

- A mayor cantidad de estímulos dirigidos por el diseño museográfico con intensión pedagógica, mayor interacción y, por lo tanto, mayor aprendizaje.

- En los museos no solo se aprenden contenidos, sino formas de participación y además, se practican habilidades cognitivas intra e intersubjetivas.

- Es posible desde el diseño museográfico controlar el tipo e interacción y por lo tanto, promover los aprendizajes deseados (Rodríguez, 2011).

\subsection{La Musa del Poder: hacia un Museo Integral con la sociomuseología}

La sociomuselogía es un campo de investigación y práctica que deriva de la madurez de la nueva museología Latina conocida desde el siglo XX como museología comunitaria. Se caracteriza por poseer una perspectiva del rol social del Museo y de la herencia, como herramientas de empoderamiento por parte de los grupos humanos (Dos Santos, 2010).

Se considera que la Nueva Museología ha cambiado, en tanto la sociedad lo ha hecho también, y esa transformación se evidencia para el caso de la sociomuseología en el vínculo del Museo con comunidades de práctica. Esta tendencia se ha desarrollado especialmente en Portugal, Brasil y Amsterdam.

Dos Santos (2010) expone que la experiencia que implementó la Nueva Museología en los eco Museos Comunitarios se traslada con la sociomuseología a los centros urbanos con una perspectiva nueva, la cual Heijnen (2010) define los propósitos del Museo como una disciplina teórica y humanista, pero en función del desarrollo social, donde la toma de 
decisiones sobre la interpretación de la herencia se realiza departe de las comunidades. La herencia más que un asunto individual, se considera un asunto colectivo.

Giménez-Cassina (2010) señala que de la Nueva Museología se deriva dos enfoques:

- El anglosajón que considera a la museología una ciencia y al Museo una plataforma educativa. Donde el concepto de identidad se realiza con base en agrupaciones de factores externos (género, etnicidad, nacionalidad, clase social y similares) como una definición impuesta. Desde esa perspectiva de identidad, se hace la defensa de la herencia natural y de la cultural. Los proyectos museográficos inician en el Museo y luego se facilitan procesos con la comunidad para su gestión.

- El Latino que se denomina Sociomuseología y se vincula con el concepto de Museo Integral que considera que comunidad-territorio-herencia conforman una sola unidad. En este caso, el grado de poder de la comunidad es mayor que en el enfoque anterior, especialmente en el concepto de la exposición y la forma en que debe ser presentado un tema de herencia o identidad al público. Por lo anterior, los proyectos deben iniciar con la comunidad y luego el Museo facilita su gestión junto con ella mediante procesos de trabajo cooperativos que enriquecen la memoria de la herencia. Se trabaja con grupos de discusión dirigidos por un profesional. Este enfoque se ha desarrollado en espacios urbanos que han sido golpeados por la globalización y donde lo local ha requerido un espacio de expresión identitaria.

\subsection{La Musa crítica: hacia una museología transformativa}

Si bien la museología crítica es originaria del siglo $\mathrm{XX}$, se ha mantenido en el siglo XXI como una perspectiva exógena de los museos, planteada más por académicos que por trabajadores de museos (Lorente, 2006).

Uno de sus destacados expositores es Lorente (2006), quien indica que esta tendencia busca promover el pensamiento crítico constructivo versus el dominante y exacerbar las interpretaciones subjetivas de la realidad. Ese aporte debe generar transformación social. En este sentido, interesa un cambio orientado por la crítica y desde el espacio museal.

La Museología crítica es una versión de la teoría crítica adaptada al quehacer museal, donde en sus inicios el marxismo sienta las bases y luego la dialéctica hegeliana tiene un papel central en el concepto de la contradicción discursiva para generar la transformación 
social. En síntesis, el concepto transformacional está vinculado con la necesidad de no solo contar con una perspectiva crítica de la sociedad, sino lograr el cambio deseado.

Una museografía crítica procura generar discusión sobre las explicaciones dominantes y buscar alternativas de diálogo para la interpretación de la realidad en discusión, pero sobre todo para instar al cambio social.

\subsection{La Musa dialógica o el museología dialógica}

La propuesta del Museo dialógico es interdisciplinar, pues se consideran aspectos de las ciencias de la comunicación, la neurología, la pedagogía, la psicología, la sociología y la epistemología.

Según Araniev (2011), el descubrimiento de las llamadas "neuronas espejo" mostró que la afirmación de Fichte, filósofo del siglo XIX, en relación con que no hay sujeto sin objeto y no hay objeto sin sujeto, tiene un fundamento biológico, y que la mente humana está condenada al diálogo. Por lo tanto, el Museo que es objeto y sujeto de la conciencia es en esencia dialógico.

El autor explica que las neuronas espejo son el fundamento de la comunicación y la base neurológica del mecanismo que crea la conexión entre quién envía un mensaje y quién lo percibe, sin necesidad de elaborar una mediación cognitiva.

Desde esta perspectiva, el interés no está en promover el diálogo, sino en reflexionar sobre el diálogo. Esa reflexión es la que permite comprender el verdadero significado del diálogo humano. Los estudios de visitantes de museos, en este caso, tratan de observar a los observadores. En síntesis, la premisa central consiste en comprender que cualquier museo es dialógico por la naturaleza de la mente humana.

Brulon (2011) explica a la Museología dialógica utilizando una metáfora en la cuál indica que esta tendencia es como una representación teatral de la realidad donde el público es parte de la puesta en escena. El dialogismo que se da en ese encuentro es la obra misma, la cual es susceptible de investigación y central en el proceso de comprender el fenómeno museal.

El problema que ofrece este enfoque consiste en que no siempre el Museo desea escuchar a sus visitantes, ya sea porque sus críticas atentan contra sus intereses o porque no se comparten ciertas ideas. 
Si bien es cierto que el Museo en esencia es dialógico, es posible también promover el diálogo mediante diferentes técnicas o estrategias didácticas, tales como la resolución de conflictos y el análisis de casos. El aprendizaje dialógico es una forma de utilizar competencias sociales y comunicativas, ya que la construcción de los significados están relacionados con las interacciones humanas (Hernández. 2011).

La arquitectura misma es considerada importante como escenario dialógico donde no sólo se establece una comunicación con la exhibición, sino también con el edificio. Según Hernández (2011), los visitantes del siglo XXI requieren exposiciones dialógicas, o sea, abiertas, interactivas e inclusivas donde se pueda discutir, dialogar y reflexionar.

\section{Ejes de cambio en el quehacer museal del siglo XXI}

\subsection{La Musa digital}

Vieregg (2002) señala que en el ámbito museal, durante el siglo XX la ciencia usurpó la atención que el arte había ocupado en el siglo XIX. En el siglo XXI la tecnología virtual será un interés central, aunque incorpore el arte y la ciencia en sus temáticas de abordaje. Presenciamos en el Museo del siglo XXI, no solo la relación entre visitantes y el objeto, ahora tenemos una triada que agrega elementos del mundo virtual.

Oportunamente, Desvallées (2002) se pregunta ¿es ese mundo virtual parte de la herencia intangible, es algo real o es una abstracción? ¿Llegará el momento en que en el Museo catalogaremos objetos (hologramas) sin coleccionarlos? La virtualización técnica de la realidad nos introduce al mundo virtual como si fuera el mundo real. Esta situación favorece la recreación de experiencias que es lo que el público desea consumir, pero también nos plantea un problema epistemológico importante.

Si bien hemos heredado del siglo XX una serie de avances tecnológicos que han revolucionado nuestra realidad del mundo de la comunicación y de la información, el siglo XXI nos ha sorprendido con la web 6.0 y los cambios que vienen son sumamente grandes y rápidos. La generación de imágenes en 3D desde una fotografía digital, el foto-realismo del 
mundo virtual, las aplicaciones vinculadas al GPS ${ }^{2}$, los RFID tags ${ }^{3}$, la telefonía celular muy comercializada y con diversas aplicaciones que van incorporándose poco a poco y particularmente desde este año, a las llamadas exhibiciones de realidad virtual (Hirose, 2006) y que definitivamente tendrán una importancia transcendental en los estudios de visitantes a museos en cuanto a la fiabilidad y validez en el registro de datos. La exhibición de vitrinas virtuales, cuyo foco de atención es un objeto virtual en 3D, mediante un holograma, hace que nos traslademos a nuevos escenarios expositivos y a nuevas formas de orientar las interacciones.

La American Association of Museums (2011) ha reportado que en los EE.UU un tercio de los museos planean crecer hacia aplicaciones con los teléfonos inteligentes, ya que actualmente la tecnología celular de audio es la más utilizada.

Indican que el uso más común en cuánto a tecnología celular es la técnica del recorrido con audio mediante aparatos provistos por los museos y los recorridos mediante teléfonos celulares. Sólo un museo de los 20 estudiados está utilizando aplicaciones con la telefonía inteligente y los recorridos multimedia desde sus propias plataformas. Es posible encontrar aplicaciones de museos para la telefonía inteligente en formato de juegos, guías de recorrido y actividades. Esta modalidad proyecta un crecimiento rápido en EEUU. También, se encuentran los recorridos diseñados para los Ipad y, por último, en la mensajería de texto se utilizan las trivias y otros juegos.

Lo interesante de los recorridos con audio es la amplia posibilidad que ofrece cuando se cuenta con recorridos alternativos. Por ejemplo, es posible que una exhibición histórica cuente con varias guías de audio a escoger por el visitante. Así, la historia que acompaña a la exhibición puede ser narrada desde un enfoque masculino, o desde la perspectiva femenina, con un enfoque teórico marxista, o podría hacerse el recorrido con un audio que siga una narración sistémica y, además, se podría regresar otro día por una explicación histórica desde el funcionalismo. Esto engancha a cierto tipo de visitante a regresar por diferentes formas de comprender una misma colección.

2 GPS es Global Positioning System. Es un sistema que mediante satélites ubica a cualquier dispositivo GPS y da su localización geográfica.

${ }_{3}$ RFID es Radio Frecuency Identification. Es un sistema similar a la lectura de código de barras, pero más rápido y por frecuencia de radio lo que permite una localización a mayores distancias. No requiere línea de visión, simplemente son etiquetas que se ubican en un lugar y desde ahí son leídas por frecuencia de radio. 
Por su lado, tradicionalmente los museos han utilizado una combinación de impresos para divulgar, informar y guiar a sus visitantes en las exhibiciones, algunos son los desplegables, los mapas, el audio, las guías impresas y otros similares. Según Aggarwal (2011) todos esos impresos se pueden sustituir con la conectividad móvil a internet gracias a la telefonía inteligente. Un ejemplo de esto es una exposición del Instituto Lloyd donde al pié de cada pintura se colocó una dirección web la cual al ser accedida se obtenía información sobre ella, la ubicación de esa pintura en relación con las otras y sobre la cantidad de personas que habían accedido a la información. Esto, a su vez, permite el registro de visitantes y su respectiva base de datos para investigación.

\subsection{La Musa del consumo}

Ritzer y Stillman (2003) afirman que, en la actualidad, el acto de consumir productos ha perdido terreno respecto el acto de consumir experiencias en el tiempo libre. Este tipo de consumo se sitúa en la búsqueda de estímulos sensoriales, enriquecimiento intelectual y recreación.

Los autores señalan que el museo es un espacio privilegiado en el consumo de experiencias, por lo que un fracaso en la competencia con otras experiencias de consumo puede llevar al declive de la visitación. Sin embargo, en algunos casos esto se ha llevado al extremo de la "Disneyzación" del museo o de la inmersión de la institución museal en ciudades fantasía tipo Orlando y Las Vegas, para así atraer el turismo. El gran peligro de competir con estos sectores recreativos es que la identidad museal se diluya al punto de dejar de ser museo y pasar a ser un parque temático.

Ahora bien, el peligro de pasar de museo a parque temático se da porque existen cuatro mecanismos principales que señalan el éxito de las catedrales del consumo y que es posible encontrarlos en los museos (Ritzer y Sillman, 2003), ellos son:

1. Simulación: se logra con las representaciones museográficas de la realidad, que son una puesta en escena de interpretaciones de fenómenos y escenas culturales. Si bien la exhibición del objeto en contexto es un logro de la nueva museología. La experiencia de participar con esos objetos es algo reciente y ha generado mucha atracción al consumo de la experiencia museal. Esta simulación puede amenazar el sentido de la experiencia original de quiénes en el pasado o en otro contexto los utilizaron. Por ejemplo, los sellos indígenas precolombinos aunque en una exhibición 
se coloquen en contexto, al ser manipulados, la experiencia de su uso está fuera de contexto y esto cambia el sentido cultural de su uso.

2. Implosión: se da con el crecimiento de la institución museal en cuanto a servicios paralelos, tales como, restaurantes, hoteles, tiendas de ropa, tiendas se souvenir, cafeterías, entre otros. Un ejemplo es La Galería Nacional de Washington D.C. que cuenta con dos grandes espacios para estos servicios.

3. Manipulación del tiempo: la atemporalidad y la reducción del tiempo, por medio de exhibiciones, ha sido una herramienta propia del Museo y uno de sus atractivos. Esto puede también ofrecer una falsa impresión del transcurso del tiempo y de los procesos que se desean representar.

4. Manipulación del espacio: se ha comprendido en el ámbito de museos que la arquitectura es tan importante como la exposición; de hecho, los visitantes muchas veces tienen claro que visitan ambos. Ejemplo de lo anterior es la monumental arquitectura del Museo Louvre en forma de pirámide y en nuestro caso el Museo de los Niños ubicado en la Antigua Penitenciaría Central. En este sentido, Ago (2007) reporta que en la nueva legislación de China del 2002, que entró en vigencia desde el 2005, se destaca el aprecio por los diseños arquitectónicos de los últimos años, que se acompañó por novedosos proyectos en esa línea como el Museo de Janchuan.

Los llamados museos franquicia son un ejemplo de lo citado anteriormente ${ }^{4}$ cuentan con gran infraestructura que es parte de la atracción, implosión, simulacros o representaciones donde se cuenta con exhibiciones permanentes y temporales, así como locales comerciales y restaurantes.

En este sentido al visitante se le llama consumidor y su criterio moldea en el mejor de los casos el "producto" museográfico o educativo que se ofrece. Es posible dejar en el olvido el concepto de Museo para transformarse en un parque temático donde las atracciones y el entretenimiento son el eje de la experiencia del visitante y desde ahí se captar el turismo y, por lo tanto, las finanzas.

Fernández (2003) hace dos fuertes críticas a la experiencia de consumo como eje de cambio en los museos

4 Ver el caso de la franquicia Gehry disponible en http://esferapublica.org/nfblog/?p=4075 
Los actuales museos no son templos invadidos por mercaderes, sino comercios dirigidos por sacerdotes (p. 5). Eso para el caso de las colecciones en edificios patrimoniales de las catedrales europeas. (...) Los museos han sucumbido a la tentación del espectáculo sustituyendo la conservación y el estudio por una programación de atracciones que los ha hecho a la vez más numerosos y más intrascendentes, más poderosos y más frágiles, más visibles y más vacíos. (p. 5)

Esa unión del patrimonio con nuevos productos culturales genera una relación entre el museo y las industrias culturales. Martínez (2006) refiere este fenómeno como la transición de la museología del objeto hacia el sujeto. De ahí el enfoque en el entretenimiento como medio para generar sensaciones en los consumidores para su placer, que por naturaleza es temporal. Los estudios de marketing orientan el quehacer museal de manera muy diferente que lo hace la sociomuselogía. La imagen de los productos museales se moldea desde el marketing. Sin embargo, este marketing debe comprenderse como una forma de alcanzar los objetivos museales y de llegar a diferente público, no solo para generar experiencias sensoriales de consumo que permitan la obtención de ingresos (Sandell y Janes, 2007 y Kotler y Kotler, 2001).

Pareciera que esta tendencia, de focalizar las acciones hacia el sujeto, es cada vez más fuerte en los museos. Sin embargo, resulta indispensable pensar esa transición más, no olvidar al objeto y tal vez podríamos descubrir que lo que nos interesa es que el objeto y el sujeto dialoguen y se encuentren. ¡Eso también es divertido!

\subsection{La Musa museal}

Suchy (2006) expone que para el siglo XXI resulta indispensable hacer comunidad de aprendizaje que oriente las acciones a futuro, porque el adelanto tecnológico y la inmersión en el mundo virtual es cada vez más acelerada y esos cambios que debemos hacer no deben ser filtraciones accidentales, sino procesos debidamente pensados sin olvidar la misión del Museo y su función en la sociedad en tanto institución que resguarda la herencia material tangible y no tangible de grupos particulares y la universal.

La autora también indica que en este siglo, más que en los anteriores, se requiere la construcción de un contexto museal de diálogo que oriente ese cambio. Necesitamos buenos proyectos, pero también líderes con fuertes pasiones afines al rumbo que el Museo debe 
seguir: que representen nuestras historias familiares y comunales, que sientan pasión por la historia de nuestros pueblos y por el conocimiento universal, por las realidades con las que dormimos, nos levantamos y vivimos, pero sobre todo por el cambio que la sociedad requiere.

Suchy (2006) propone la creación de un capital social (museal) que utilice el distintivo de la sílaba "co": comités, códigos, consumidores, concilios, cooperación, coordinación, cohesión, colaboración, consulta, comunicación, colección, complejidad, construcción, conservación, cognición, contemplación, colectar, conexión, control, contexto, consideración, compasión y competencia en un espíritu de diálogo y conciliación. Lo anterior debe ser meditado junto con la propuesta de Poll y Asencio (1997) quienes nos recuerdan que las teorías de la mentalidad de los profesionales en museos, construidas en la práctica museal cotidiana, requieren ser revisadas a la luz de las investigaciones y requieren de soportes científicos que hagan del quehacer museal un trabajo más asertivo.

Igualmente, encuentran que los curadores, los educadores y los diseñadores tienen altos niveles de desacuerdo respecto del trabajo museográfico. Por ejemplo, de esos tres grupos los curadores son los que peor detectan la efectividad de los montajes, pese a que todos los grupos tienen baja capacidad para ello. Necesitamos basarnos en datos reales y tener cuidado con las percepciones particulares y de gremios, estar abiertos a otras formas de ver el museo y someter los criterios de diferentes disciplinas a evaluación en el contexto de resultados de investigación certera.

Genoways (2006) recomienda que los profesionales en museos debemos ser parte de una asociación profesional internacional de museos, debemos acreditar los programas académicos relacionados con la museología para asegurar niveles altos de formación, publicar en revistas divulgativas y también en revistas científicas sobre nuestro quehacer museal.

En nuestro ámbito, se cuenta con IBERMUSEUS que es una red de museos enfocada a la articulación, fomento y promoción de políticas públicas entre los museos iberoamericanos (http://www.ibermuseus.org/es/). Además, está REDCAMUS, que es la Red Centroamericana de Museos que está afiliada a IBERMUSEUS. En Costa Rica, los museos estatales y algunos privados están vinculados con REDCAMUS, también muchos profesionales se han afiliado a ICOMOS, y en el caso del Ministerio de Cultura y Juventud se 
cuenta con la sección de Museos comunitarios y Regionales, una red que articula ese tipo de museos y experiencias.

En síntesis, tenemos un llamado a construir una comunidad de aprendizaje colaborativo, que permita orientar los cambios y no dejar que el azar nos lleve a su antojo por la vida. Necesitamos dialogar, investigar e integrar.

\section{Conclusión}

Las metas del Museo han cambiado para el siglo XXI, interesa más la forma de exposición que los objetos mismos. El tradicional concepto de Museo como institución educativa dedicada a colectar, investigar sus colecciones y educar sobre sus colecciones hoy queda incompleto, dejándonos una sensación de que "falta algo". Esta sensación se divisa desde el momento en que las investigaciones de visitantes nos hacen comprender al "otro" o sea al visitante. Ese visitante que no nos puede resultar extraño, pues al entrar en nuestros espacios de trabajo se convierte en actor y transforman el sentido social de una exhibición, re-construye el significado de los objetos y la misma identidad del Museo.

El nuevo componente en la definición de Museo es, en esencia, un espacio de experiencias sociales. Debemos incluir al visitante en la definición de lo que es un Museo.

Estos nuevos lineamientos museales conllevan el riesgo de olvidar al objeto o colección en el proceso educativo y centrarse en los intereses y gustos del sujeto. En este sentido, resulta vital la promoción del diálogo sujeto-objeto para que la función educativa del Museo contribuya en la conformación una sociedad con conciencia histórica-cultural clara.

Sabemos que en los museos no sólo aprendemos los contenidos que tratan los programas educativos y las exhibiciones, sino que aprendemos el lenguaje de comunicación de la museografía, con el cual dialogamos con los museógrafos y la colección. Visitar un Museo es aprender un lenguaje, también es comunicarse de otra forma, es una experiencia intrasubjetiva, intersubjetiva, física y virtual. Lo anterior no significa dejar de lado al objeto, necesitamos que el objeto y los sujetos dialoguen, se encuentren, que el pasado y el presente hagan la guerra o la paz.

Esa transición del objeto al sujeto está presente en el diseño de experiencias sensoriales para el consumo del público, en el uso de la interacción como mecanismo lúdico y de aprendizaje de las personas, en la explotación de la imagen del museo por medio del marketing para atraer públicos, en cederle el poder a la comunidad para definir sus museos y 
en la sustitución del objeto real por el virtual. Esa transición debe ser pensada y orientada hacia una visión y con una misión claramente definida. ¡Qué la musa museal nos inspire!

\section{Referencias}

Aggarwal, Arnav, Molines, Sébastian y Wei, Lai. (2011). Smartphones Let Loose-The Museological Potencial of Wireless Technology. The University of Dublin. Recuperado el 21 de octubre de 2011 de http://www.scss.tcd.ie/publications/techreports/reports.11/TCD-CS-2011-02.pdf

Ago, Fabrizio. (2007). Towards a New Museology in China. En Hildegard K. Vieregg (Ed.) Museology and Techniques (p. 19). International Council of Museums. International Council of Museums ICOFOM.

American Association of Museums (AAM). (2011). Mobile Technology Survey. Guide by Cell. Fusion Research + Analitics. Documento interno de la AAM. EEUU.

Araniev, Vitaly. (2011). The Dialogic Museum, Dice and Neurons; A few personal notes of the topic. En The Dialogic Museum and the Visitor Experience. ICOM. ICOFOM. Working papers. Recuperado el 15 de octubre de 2011 de http://network.icom.museum/fileadmin/user upload/minisites/icofom/pdf/ISS\%2040\%2 oWorking\%20Papers.pdf

Brulon Soares, Bruno. (2011). Experiencing Dialogue: Behind the Curtains of Museum Performance. En: The Dialogic Museum and the Visitor Experience. ICOM. ICOFOM. Working papers. Recuperado el 15 de octubre de 2011 de http://network.icom.museum/fileadmin/user upload/minisites/icofom/pdf/ISS\%2040\%2 OWorking\%20Papers.pdf

Desvallées, André. (2002). Museologie et expologie: du réel au virtual. En Hildegard K. Vieregg (Ed.), Museología y presentación: ¿Original o virtual? (pp.56-65). International Council of Museums. ICOFON.

Dos Santos, Paula A. (2010). To Understand New Museology in the $21^{\text {st }}$ Century. Sociomuseology 3: To Understand New Museology in the $21^{\text {st }}$ Century. Cuadernos de Sociomuseología, 3 (37), 5-12.

Fernández Galiano, Luis. (Febrero, 2003). Mil Museos. Musa: revista de las instituciones del patrimonio histórico de Andalucía, (1), 5.

Genoways, Hugh H. (2006). To Members of the Museum Profession. En Hugh H. Genoways (Ed.), Museum Philosophy for the Twenty-first Century (pp. 221-234). EE.UU.: Altamira Press.

Giménez-Cassina, Eduardo. (2010). Who I am? An Identity Crisis. Sociomuseology 3: To Understand New Museology in the $21^{\text {st }}$ Century. Cuadernos de Sociomuseología, 3 (37), 25-42. 
Heijnen, Wilke. (2010) The New Professional: Underdog or Expert? Sociomuseology 3: To Understand New Museology in the $21^{\text {st }}$ Century. Cuadernos de Sociomuseología, 3 (37), 13-24.

Hernández Hernández, Francisca. (2011). Museo dialógico y comunicación social. The Dialogic Museum and the Visitor Experience. International Council of Museums. ICOFOM. Working papers. Recuperado el 15 de octubre de 2011 de http://network.icom.museum/fileadmin/user upload/minisites/icofom/pdf/ISS\%2040\%2 oWorking\%20Papers.pdf

Hirose, Michitaka. (2006). Virtual Reality Tecnology and Museum Exhibits. The International Journal of Virtual Reality, 5 (2), 31-36.

Kotler, Neil y Kotler, Philip. (2001). Estrategias y Marketing de museos. Ariel Patrimonio Histórico. España.

Lorente Lorente, Jesús Pedro. (2006). De vueltas con la museología crítica: nuevas tendencias en teoría museológica. Revista Museos.es (2), 24-33.

Martínez Yañez, Celia. (2006). El patrimonio cultural de los nuevos valores, tipos finalidades y formas. Tesis doctoral. Facultad de Filosofía y Letras, departamento de Historia del Arte, Universidad de Granada. España.

Pol, Elena y Asensio, Miguel. (1997). ¿Porqué es efectivo un montaje?: Un estudio sobre las teorías de profesionales del Museo. Boletín de la ANABAD, 47 (1), 177-195.

Ritzer, George y Stillman, Todd (febrero, 2003) El museo como catedral del consumo: desafíos y peligros. Musa: revista de las instituciones del patrimonio histórico de Andalucía, (1), 32-34.

Rodríguez Sánchez, Keilyn. (agosto, 2011). Estudios de Visitantes a Museos. Revista Actualidades Investigativas en Educación, 11(2). Disponible en http://revista.inie.ucr.ac.cr/buscararticulos/controlador/Article/accion/show/articulo/estudios-de-visitantes-a-museos.html

Sandell, Richardy y Janes, Robert. (2007). Museum, Management and Marketing. Nueva York: Routledge.

Sushy, Sherene. (2006). Connection, Recollection, and Musseum Missions. En Hugh H. Genoways (Ed.) Museum Philosophy for the Twenty-first Century (pp. 47-58). EE.UU.: Altamira Press.

Wagensberg, Jorge. (2005). The Total Museum, a Tool for Social Change. Historia, Ciencias, Saúde-Manguinhos, 12 (Supplement), 309-321. 